\title{
PARADOJAS DEL PLURALISMO
}

\author{
Arturo Calvo Espiga \\ Abogado del Tribunal de la Rota de Roma
}

Sumario: 1. Acercamiento al concepto de pluralismo. a) Pluralismo y democracia. b) Pluralismo y libertad. c) Pluralismo y verdad. d) Pluralismo y compromiso. 2. El pluralismo en su dimensión científica. 3. Perspectiva filosófica del pluralismo. 4. Pluralismo, persona y sociedad. 5. Pluralismo y política. 6. Futuro y perplejidad.

La dificultad de precisar la significación de este concepto, según el uso que del mismo se hace en medios que van desde el ámbito de lo jurídico a la sociología o al manido recurso mitinero, radica en su radical polisemia fraguada, sin duda alguna, en galernas de conveniencia. Ello nos aboca a comenzar este ejercicio de reflexión sobre las palabras desde el cañamazo significativo más elemental en que se articulan letras y razones.

En el habla común del español, se entiende por pluralismo: «sistema por el cual se acepta o reconoce la pluralidad de doctrinas o métodos en materia política, económica, etc.», según el Diccionario de la Lengua Española editado por la Real Academia ${ }^{1}$.

O bien, «1. Pluralidad. Existencia de distintas tendencias de carácter político, económico o religioso que pueden expresarse libremente. 2. Fil. Doctrina opuesta al monismo, que supone el mundo formado por individuos y conjuntos de individuos», conforme a la obra de María Moliner, Diccionario del uso del español; en el que se entiende por pluralidad, «circunstancia de ser más de uno: "El asunto tiene pluralidad de aspectos". Multiplicidad».

O también, «1. a) Pluralidad de ideas o tendencias... b) Tendencia que defiende el pluralismo... 2. (Rel. Crist.) Acumulación de varios puestos eclesiásticos en una persona. 3 (Filos.) Doctrina que admite más de un principio o sustancia», entendiendo por pluralidad, «1. Condición de plural. 2. Conjunto de personas o cosas» y por plural, «(lit.) Múltiple o vario. b) (Gram.) [Número] que expresa pluralidad. c) (Gram.) [Forma] que corresponde al número plural» ${ }^{2}$.

121 ed. (1992).

2 M. SeCo, O. Andrés y G. Ramos, Diccionario del español actual (Madrid 1999). 


\section{Acercamiento al concepto de pluralismo}

Se suele entender por pluralismo el conjunto de circunstancias sociales y actitudes personales que conforman y delimitan ámbitos de convivencia en que el poder, sea político, económico, cultural, ideológico, etc., está justa y equitativamente distribuido, compartido y reconocido, haciendo, en consecuencia, innecesaria la tolerancia, ya como actitud, bien como hecho, tanto activa (ser tolerante) como pasiva (ser tolerado), porque cada cual se mueve libremente en el ejercicio de sus capacidades, la expresión de sus opiniones y la puesta en práctica de sus ideas a través de determinados comportamientos: pues, estamos frente a lo que se denomina, en perífrasis más profunda y comprometida que lo que pudiera parecer a primera vista, «democracia como forma de vida o como cultura». Es decir, se trata de la democracia «no sólo como un específico régimen de organización y gobierno político, sino ante todo como una cultura global y universal, como forma de vida individual y comunitariamente valiosa» ${ }^{3}$.

\section{a) Pluralismo y democracia}

ARANGUREN llega, incluso, a hablar no sólo de una «moral democrática», sino de la propia democracia como moral: «Entiendo así la democracia, antes que como una forma política concreta, como la tarea -infinita - de democratización de la sociedad, de compromiso con ella, de engagement total, según la expresión de Sartre, de democratización a todos los niveles, el estrictamente político, por supuesto, pero también el económico y el industrial, el de la democracia cultural y el de la democratización de la vida y los compromisos sociales, familiares...» ${ }^{4}$.

En esta misma línea, pero desde la perspectiva del conflicto social y de su superación, se expresa BARCELLONA: "La democracia es un valor porque en el mundo de la falta de fundamentos y del artificio realiza el derecho mínimo de cada uno a poder decidir el sentido de su propia historicidad. Pero precisamente por esto la democracia es inseparable del conflicto... El conflicto que estructura la democracia lleva en sí, inevitablemente, el valor de la convivencia, pues de por sí consiste en la posibilidad de un orden infundado $y$, por tanto, de un orden que se hace cargo de la pluralidad de las razones, de la posibilidad de

3 J. QUEREJAZU, «Perplejidades de la tolerancia», Lumen 43, 1994, 48-49.

4 J.L. LóPEZ ARANGUREN, Etica de la felicidad y otros lenguajes (Madrid 1988) 117. 
que una gane y otra pierda, sin ser negada definitivamente por ello» ${ }^{5}$. Democracia y pluralismo se coimplican y complementan tan necesaria y absolutamente que no puede darse una sin la presencia del otro.

Por más que se insista en ello, siempre nos quedaremos cortos en la pretensión de definir o delimitar en y desde todas sus perspectivas e implicaciones el pluralismo ${ }^{6}$. De entre toda la compleja red de relaciones en que se articula este concepto, nos interesa señalar aquí, sobre todo en cuanto perspectiva metodológica, el hecho de que los requisitos, condiciones y presupuestos que posibilitan el ejercicio del pluralismo se profundizan, maduran y enriquecen con su ejercicio y puesta en práctica. En este sentido, pluralismo y requisitos de ejercicio se integran en una dialéctica positiva de crecimiento en espiral: a mayor pluralismo, mejores condiciones y posibilidades de un ejercicio que, a su vez, magnifica y facilita los requisitos que acaban haciendo progresivamente más necesaria la existencia del pluralismo.

\section{b) Pluralismo y libertad}

Entendido así, el pluralismo enraíza y se consolida en una concepción del hombre basada, desde el convencimiento jurídico-formal y el reconocimiento práctico-material, en la dignidad humana, así como en los atributos y características en ella implicados y en los derechos personales y sociales que de ella derivan; y sólo es posible en condiciones, formales y materiales, de igualdad y libertad ${ }^{7}$, como única posibilidad de realización material y formal de la justicia, pues sólo cuando se consiga una realización tal de la igualdad que nunca la libertad de una persona pueda ser invocada como límite cercenador de la de otras se habrá consolidado la auténtica justicia, irrefutable testigo del verdadero pluralismo.

De este modo, en una sociedad pluralista, la libertad personal de los individuos que la componen jamás podrá ser invocada como límite de

5 P. Barcellona, Postmodernidad y comunidad. El regreso de la vinculación social, (Madrid 1992) 131-132

6 Apuntamos, aunque dadas las características de este trabajo remitimos su tratamiento a un estudio posterior, la influencia que, en la formulación, sistematización y práctica de esta categoría, ha tenido la hermenéutica formulada en torno al pluralismo teológico.

7 «Frente a situaciones de uniformidad obligada o de marginalidad impuesta, la igualdad reivindica la participación de todos, personas y colectivos, en el escenario de la pluralidad, de forma que todos estén en él a título de protagonistas. No es un escenario a compartir entre élites, sino el foro donde todos encuentren espacio, lugar y fuerza... Una libertad que, lejos de constituirse en sinónimo de permisividad, se construya y realice en clave de responsabilidad, es decir, como capacidad de dar y de exigir razón coherente y suficiente de cada opinión, convicción, creencia, conducta...» (J. QUEREJAZU, o.c., pp. 50 y 54). 
la de los demás, según la asumida y manida máxima de que «mi libertad termina donde comienza la de los demás»; antes al contrario, habrá que afirmar, a partir de una relación de dialecticidad positiva entre los miembros de cualquier sociedad, que la libertad de cada uno de ellos se acrece y consolida en la medida, y sólo en la medida, en que se expande y fortalece la libertad de los demás.

Nos hallamos, pues, ante una estructura o dinámica dialéctica del tipo de la que hace dos décadas planteábamos a la hora de explicar la complejidad de la Iglesia y de su derecho y en la que los elementos que integran la relación entre ambos «se implican mutuamente, de manera que no puede existir el uno sin el otro, pues ambas existencias se necesitan; y, al mismo tiempo, sustantivar cualquiera de esos elementos conduce inexorablemente a la adjetivación del otro y en el caso límite a su negación, consiguiendo paradójicamente, en este caso, la negación de sí mismo» ${ }^{8}$. Abundando en esta misma idea, escribíamos dos años después: "Precisamente, en razón de esta misma dialecticidad, la afirmación unilateral y exclusiva de alguno de los extremos mencionados tendría como consecuencia no sólo la negación del no afirmado, sino la aniquilación misma de lo afirmado unilateralmente»9${ }^{9}$.

Así pues, el derecho o el ejercicio de la libertad del otro nunca puede ser límite del ejercicio del propio derecho o libertad; antes al contrario, es condición sine qua non que necesariamente debe existir para posibilitar su propia existencia y efectividad práctica, pues, en la medida en que mi derecho roce o lesione el ajeno, se estará negando a sí mismo. Por ello, estimamos que no se puede estar de acuerdo con POPPER

8 A. Calvo Espiga, «En torno a la raíz teológica del Derecho Canónico Fundamental», Lumen 32, 1983, 31.

9 A. Calvo Espiga, «Acercamiento a la incidencia del derecho natural y de los derechos humanos en la elaboración del derecho», Scriptorium Victoriense 32, 1985, 292. «Así se supera la torpe idea que considera la libertad del otro como límite y, por tanto, estorbo para la propia. La libertad ajena, de los otros, es indispensable condición de posibilidad para la propia libertad» (J. QueREJAZU, o.c., p. 54). En parecido sentido se expresa MoHAMED TALBI: «Dans une société équilibrée, régie, non par les rapports de force, mais par le droit, la liberté de l'autre est la mienne, et vice-versa.

En effet, sans la liberté de l'autre, en droit, la mienne n'existerait tout simplement pas. En pratique, on sait combien cependant on est encore trop souvent loin du compte dans tous les régimes où la force l'emporte sur le droit. Pire! Les distorsions portées à la liberté peuvent "se justifier". Les totalitarismes ont leur propre logique et n'ont jamais manqué de théoriciens. Une idéologie opuse l'autre, et dans certains circunstances la raison chavire et perd ses droits» (M. TALBI, «Les réactions non catholiques à la Déclaration du Vatican II Dignitatis Humanae: Point de vue musulman», en Varios, Paolo VI e il rapporto Chiesamondo al Concilio, Brescia 1991, 231). Puede verse, también, D. LlamaZAREs FernánDEZ, Derecho Canónico Fundamental (León 1980) 42-43. 
cuando, con pie en el dicho de un juez americano, afirma que «el límite de tu libertad para mover tus puños como te parezca y guste es la nariz de tu vecino» ${ }^{10}$.

POPPER, como tantos otros teóricos del Estado y de la sociedad, concibe ambas realidades desde una perspectiva estatalista-societaria, no desde una dimensión personal/personalista. Robinson Crusoe, en la soledad de su perfil mítico, es libre, pero no es esencial y absolutamente libre, como pudiera parecer desde una perspectiva superficial, porque socio-comunitariamente no tiene el contraste de otra persona como referencia o equivalente dialéctico-positivo de una de las dimensiones esenciales de la libertad. De ahí que urja la necesidad de concebir las libertades fundamentales de las personas desde el ámbito o perspectiva de la subjetividad personal más que desde la dimensión pública de los ordenamientos.

En la medida que se reconozca a la persona como valor, al margen incluso de la aceptación de la existencia de valores de raíz exclusivamente personal, se ha de aceptar que tanto las libertades como los derechos que se califican de fundamentales, ya sean considerados en su dimensión de fundantes o bien en sus aspectos prácticos de desarrollo y ambiente jurídico que posibiliten su ejercicio, tienen fundamento, constitución y estructura subjetivo-personalista; pues, en caso contrario, es decir en la medida en que se insista en su apariencia pública, su radicación se desplazaría al Estado y su ordenamiento, con el consiguiente sometimiento de la persona a las interesadas circunstancias y coyunturas sociales o temporales del «capricho» estatal de cada momento. Sólo la persona libre es capaz de reconocer y valorar la libertad en los demás ${ }^{11}$.

10 K.R. Popper, Postfacio, añadido a la publicación, editada en Munich, el año 1985, por la R. Piper Gmbhand Co., de unas jornadas celebradas en Viena entre los días 24 y 26 de mayo de 1983, bajo el título Die Zufunft ist offen das Altenberger Gespräch mit den Testen das wiener Popper-Symposiums.

11 Afirmación de complejas e importantes implicaciones sociales y políticas, cuyo tratamiento excede y desborda los límites de esta reflexión, pero que esperamos realizar en un trabajo posterior. No nos resistimos, sin embargo, a apuntar ya algunas de las graves e importantes cuestiones implicadas o supuestas en este aserto: ¿cabe el pluralismo en una sociedad integrada, en parte, por personas o colectivos que no respetan, para otros, ámbitos esenciales de libertad? ¿puede hablarse de regímenes o Estados democráticos donde no existan sistemas jurídicos pluralistas? ¿son verdaderamente democráticas y respetuosas con los derechos humanos las minorías que para preservar sus libertades y características culturales o identitarias cercenan y sofocan las libertades de las, a su vez, minorías en ellas insertas? ¿es democrático y plural el miedo a la libertad del otro por parte de minorías étnicas, sociales, culturales, políticas... que sienten peligrar su identidad por el respeto al ejercicio y práctica de aquella?... 


\section{c) Pluralismo y verdad}

Esta centralidad personal exige en la sociedad plural la definición de un ámbito de verdad y, en lógica consecuencia, la aspiración a la verdad como finalidad del propio pluralismo ${ }^{12}$. Reconocer tal protagonismo a la

12 Aunque tendremos oportunidad en un trabajo posterior de reflexionar sobre las implicaciones e interacciones entre verdad, derecho y conciencia, hemos de llamar la atención sobre la importancia que, de forma especial, a partir de 1994 ha adquirido el problema de la verdad en el debate político. Baste señalar, al respecto, el impacto que en la opinión pública mundial produjeron los trabajos de la Comisión para la verdad en Sudáfrica ${ }^{(*)}$. Incluso como institución, esta Comisión, a semejanza de las creadas en varios Estados sudamericanos, goza de una creciente consideración científica por parte de juristas y politólogos (Cf. P.-B. HAyner, Unspeakable Truths: Confronting State Terror and Atrocities, Routledge 2000). También en el arte, que tantas veces ha de disfrazarse de mentira, se busca radicalmente la verdad. Así se expresaba PiCASSO, en agosto de 1997, remedando, aunque quizás el propio pintor lo ignorase, la doctrina de DANTE sobre «la verdad enmarañada bajo una hermosa mentira»: «Todos sabemos que el arte no es verdad. El arte es una mentira que nos enseña (estimula) a aferrar la verdad, al menos aquella verdad que los humanos somos capaces de aferrar. El artista debe saber cómo ha de convencer a los demás de la veracidad de sus mentiras» (Frankfurter Allgemeine Zeitung, 23-8-1997).

(*) En 1948 el Partido Nacional(1) ganó las elecciones en el país y se inició un proceso de reforzamiento de las leyes segregacionistas(2) contra la población negra, que representa el 76\% del total. La violencia creció y surgieron grupos de resistencia al sistema político. En 1964 los dirigentes del Congreso Nacional Africano (ANC)(3), entre los que estaba Nelson Mandela, fueron condenados a prisión perpetua. El régimen segregacionista se mantuvo durante 40 años, cometiéndose graves violaciones contra los derechos humanos, la gran mayoría contra la población negra. La comunidad internacional critica y aísla a Sudáfrica por su política de apartheid(4). La situación externa y las protestas internas llevan al gobierno a negociar el fin del régimen racista. A partir de 1989 el Presidente De Clerk negocia con el ANC y finalmente en 1991 se logró finalizar con el régimen segregacionista. El 10 de mayo de 1994 Nelson Mandela fue elegido presidente. El gobierno saliente promovía una ley de amnistía para los culpables de violar los derechos humanos en esos años, lo cual era rechazado por la población negra. Finalmente, se optó por un amnistía condicionada, la cual sería otorgada a quienes reconocieran sus crímenes y colaboraran con el esclarecimiento de los hechos. Con ese objeto, el Parlamento creó, por medio del Acta de Promoción de la Unidad Nacional y la Reconciliación, la «Comisión de la Verdad y Reconciliación»(5). La idea de crear esta Comisión fue inicialmente planteada en julio de 1994 por el Ministro de Justicia, Dullah Omar, en un discurso al primer parlamento democrático sudafricano. Al mismo tiempo, la organización no gubernamental denominada «Justicia en Transición», presidida por Alex Boraine, planteó la idea de que Sudáfrica debía seguir el ejemplo de otros países y «crear una comisión que se encargara de investigar y descubrir qué originó las graves violaciones a los derechos humanos y que debía enfrentarse con el pasado, garantizando amnistía a aquellos que hicieran una revelación total de lo que ocurrió»(6).

(1) Fundado en 1914 por J.B.M. Hertzog. Buscó el apoyo de los Africaners (descendientes básicamente de holandeses, alemanes y franceses, nacidos en Sudáfrica), que pensaron que Louis Botha (primer Primer Ministro de la Unión de Sudáfrica) no daba prioridad a sus intereses y era pro británico (Cf. CH. SAUNDERS y N. Southey, A dictionary of South African 
verdad y su búsqueda en la constitución y desarrollo del pluralismo no equivale a engañosa añoranza de los excesos cometidos al amparo de determinadas objetivaciones teocráticamente hipertrofiadas de la verdad que, en última instancia, no iban más allá de ser meras coartadas de ilustrada opresión; sino que, por el contrario, aceptar la centralidad de la verdad equivale en todo proceso pluralista a asumir que la búsqueda de lo verdadero supone la aceptación de que las realidades, sobre todo, personales y sociales, así como los valores en ellas implicados y con ellas conexos, son más y van más allá de lo que nuestras ideas, convicciones, intuiciones y razones puedan proyectar o justificar en un determinado momento:

\author{
¿Tu verdad? No, la Verdad, \\ y ven conmigo a buscarla. \\ La tuya, guárdatela ${ }^{13}$
}

\begin{abstract}
History, South Africa 2001, 121). (2) Mientras que algunos historiadores establecen que los orígenes de la segregación racial se debe a los primeros colonos blancos, otros han resaltado la importancia que tuvieron las ideas que llegaron desde Gran Bretaña en el siglo XIX, o han señalado a Theophilus Shepstone como el primero en llevar a la práctica políticas segregacionistas, quien como Administrador colonial y Secretario de asuntos indígenas en Natal, decía que los africanos debían ser gobernados por separado, y obligó a las dos terceras partes de los habitantes africanos de Natal a vivir en reservas, donde eran gobernados por sus autoridades tradicionales o por jefes leales a Shepstone. Ahora la mayoría concuerda en que la ideología de la separación racial no se desarrolló hasta principios del siglo Xx, y que una gran cantidad de políticas segregacionistas no se implementaron sino hasta después del establecimiento de la Unión de Sudáfrica, y que el apartheid era una forma de segregación racial más desarrollada y comprensiva que ya tenía lugar antes de 1948 (Cf. Ibid., p. 140). (3) Fue fundado en 1912 en Bloemfontein bajo el nombre de Congreso Nacional Nativo de Sudáfrica (SANNC). Es la organización política nacional más antigua del país. Luchó durante casi 50 años para lograr la ley contra la discriminación racial. En 1956 se comprometió para lograr una Sudáfrica que perteneciera a todos. Fue prohibido en 1960. Se le forzó a estar en la clandestinidad y en el exilio por tres décadas. Durante el exilio condujo una lucha armada para lograr la liberación. Asimismo, abrió sus filas para que se adhirieran blancos y otros no africanos. En 1990 dejó de estar prohibido y empezó con negociaciones formales con el gobierno, dejando de lado sus ideas socialistas que expuso en sus orígenes. Finalmente, pudo acceder al poder en las elecciones de abril de 1994 (Ibid., p. 1). (4) Término utilizado para incluir a todas las formas de segregación racial. Se empezó a utilizar para referirse a la política utilizada por el Partido Nacional a principios de la década de los 40 para extender la segregación existente, ampliarla y aplicarla con mayor rigurosidad. Esta política se implementó luego de que el Partido Nacional ganara las elecciones en 1948 (Ibid., p. 12). (5) Comisión Andina de Juristas. Una Comisión de la Verdad para el Perú. Documento de trabajo. Lima, marzo del 2001. (6) CH. SAunders y N. Southey, loc. cit., p. 177.
\end{abstract}

13 A. Machado, Proverbios y cantares, LXXXV, dedicados a José Ortega y Gasset. La misma idea, aunque desde lo que podríamos considerar como perspectiva operativa del sujeto, la expresa el poeta en otros dos lugares de sus Proverbios y cantares: «El ojo que ves 
La propia historia de personas e instituciones enseña que al margen y de espaldas al empeño por la verdad y la autenticidad, las relaciones humanas y la convivencia social derivan, en el mejor de los casos, en simple cortesía o frívola y superficial condescendencia, cuando no en sutiles formas de explotación y poder, casi siempre antesala de reacciones irracionales, fanáticas y egoístas. En la medida en que el pluralismo sea auténtico, y no una simple actitud estratégica, ha de tender a coordinar y relacionar vital y socialmente a las personas, respetando y promoviendo su diversidad: «la concordia de espíritus está basada en el reconocimiento de una verdad objetiva, es decir, independiente de las preferencias subjetivas» ${ }^{14}$.

\section{d) Pluralismo y compromiso}

No puede, pues, considerarse auténtico pluralismo cualquier intento irenista que suponga adormecer valores, provocar la apatía del «da lo mismo» o generar la amoralidad del «todo vale»; pues, mientras la tolerancia, tal y como se ha practicado y según se ha teorizado, respeta los valores del otro, el pluralismo afirma un valor propio, por ejemplo, que la diversidad y el disenso son valores que enriquecen al individuo, a la sociedad y a la propia cosa pública. Curiosamente, el absolutismo intolerante, a pesar de su falsa y pretendida apariencia de objetividad a ultranza, es el peor enemigo que tiene la verdad:

«No es correcto plantear una situación de pretendido pluralismo allí donde la verdad no desempeña el papel de contenido, cauce y objetivo de lo humano. Sólo así personas y colectivos optimizan, en su búsqueda de la verdad, la ganancia epistemológica que aporta el pluralismo. Por el contrario, la intolerancia roba tanto la opinión crítica como la atinada, así como el beneficio del contraste con la opinión falsa ${ }^{15}$.

no es/ ojo porque tú lo veas; / es ojo porque te ve» (I), que en opinión del propio Ortega constituye una de las críticas más radicales que se han hecho del idealismo relativista; y «Los ojos porque suspiras,/ sábelo bien,/ los ojos en que te miras/ son ojos porque te ven» (XL). Años antes, en otro conjunto de poemas titulado también Proverbios y cantares, esta vez sin dedicatoria alguna, había escrito: «El que espera desespera,/ dice la voz popular./ ¡Qué verdad tan verdadera! La verdad es lo que es,/ y sigue siendo verdad/ aunque se piense al revés» $(\mathrm{XXX})$.

14 C. SAHEL, «Prefacio», en Idem (ed.), La tolerancia. Por un humanismo herético (Madrid 1993) 12; cf. también N. BILBENY, El idiota moral. La banalidad del mal en el siglo XX (Barcelona 1993) 56-72.

15 J. QueREJAZU, o.c., p. 52. 
En relación necesaria con este protagonismo de la verdad, el pluralismo exige que opiniones, actitudes, convicciones, creencias, sentimientos, etc., hayan de estar sujetos a racionabilidad y comunicabilidad; o, dicho de otro modo, han de ser decibles tanto lógica como socialmente para, de este modo, poder ser contrastadas y confrontadas racionalmente, pues sin apertura sincera, aunque crítica, a lo diverso es imposible el pluralismo: sólo así se evita que el pluralismo se convierta en cobertura o tapadera de abandonos interesados o de disimuladas y manipuladoras intolerancias. Desde el pluralismo, pues, se ha de evitar la irracional afectividad del prejuicio y asentar sus valoraciones en la equitativa racionalidad del juicio:

«A los individuos cabe exigirles que sean respetuosos con los derechos de los demás, incluso el derecho a equivocarse; pero nadie puede pedir a un ciudadano que calle sus argumentos y razones o no critique a sus adversarios políticos, ideológicos o religiosos en nombre de una supuesta sensibilidad inviolable... Más aún, puede ponerse seriamente en duda si uno es más respetuoso con la dignidad de otra persona, cuando no le advierte de sus errores y equivocaciones o no esgrime ante él sus argumentos más poderosos. Es sabido que con los locos y con los borrachos "no valen argumentos ni razones". ¿Qué es entonces más intolerante y menos respetuoso en el fondo, guardar las buenas formas y maneras ante las barbaridades ideológicas y los atavismos irracionales o ejercer la crítica racionalista (y también la autocrítica) sin duelo?» ${ }^{16}$.

Y en pareja semejanza a su entronque relacional con la persona, la reciprocidad se constituye, desde el ámbito de la personalidad, en elemento necesario, fundamental y estructurante del pluralismo, pues sólo se verifica la pluralidad cuando se exige, como máximo, en la misma medida en que se está dispuesto a ofrecer ${ }^{17}$. De este modo, la percepción, la convicción, la creencia o la experiencia ajenas se convierten, para el pluralismo, en expresión distinta y, en la diversidad, necesaria de la misma verdad que se trata de buscar y defender, puesto que la

16 A. Hidalgo, «Principios filosóficos y culturales en una sociedad pluralista», en E. GUISán (ed.), Etica laica y sociedad pluralista, Madrid 1993, 150.

17 «No es correcto plantear una situación de pretendido pluralismo, donde se someta a crítica y depuración lo ajeno sin someter lo propio al mismo tamiz; donde se pretenda ser tolerado para no tolerar; donde se busquen ventajas o situaciones de privilegio...; donde, en último término, la igualdad y la equidad se quiebren. No es correcto reivindicar tolerancia para la diferencia propia $\mathrm{y}$, desde ella, ejercer intolerancia contra los antagonistas» (J. QUEREJAZU, o.c., p. 53). 
propia búsqueda, en cuanto ejercicio noble de maduración y crecimiento humanos, es ya manifestación de verdad: «En toda cultura, la técnica, los medios y los modos del propio crecimiento y maduración personal implican necesariamente una serie de obligaciones respecto a la verdad: es necesario descubrir la verdad, ser rescatados por la verdad, decir la verdad» ${ }^{18}$.

Preguntarse por la naturaleza, el significado o los contenidos del pluralismo equivale a acercarse a una cuestión que afecta a todas las dimensiones del hombre y de la sociedad. Con mucha frecuencia, como hemos constatado a través de la significación atribuida a este término en los diccionarios anteriormente referidos, mediante esta palabra sólo se significa o constata que la realidad en que vivimos es múltiple, es decir, que se compone de individuos de toda especie: desde el mineral

18 M. Foucault, «Sexualité et solitude», en Idem, Dits et Écrits, vol. 4 (Paris 1994) 169: el texto referido fue publicado en 1981, aunque la edición de $D E$, por parte de Gallimard, fue preparada por D. DEFERT y F. EwAL en el señalado 1994. Volver a la obra de FouCAULT resulta fundamental para vislumbrar cómo se puede hablar con absoluto convencimiento de la necesidad de la verdad como referencia ineludible de libertad, pluralismo y progreso, sin caer en estériles y castrantes absolutismos. Para FoucAult, la verdad, como la locura, la muerte o el crimen, representa una de las experiencias extremas en las que intenta profundizar a partir, sobre todo, de la filosofía de Nietzsche, que había versificado: «En el Norte - lo confieso curioso-/ Amé a una mujerzuela, tan vieja que asustaba:/ su nombre era "la verdad”»; y para quien, según FouCAULT, «la cuestión de la verdad y de su historia eran centrales» («Structuralisme et post-structuralisme» [1983], en Dits et Écrits, cit., p. 444). Por ello, se ha dicho con toda justeza que «la originalidad de Foucault, muy cercano a Nietzsche desde esta perspectiva, es una etiología que no busca el origen del "poder de la verdad" y de la "hermenéutica del deseo" en el resentimiento, en la moral de los esclavos y en una universalidad que enmascara voluntades de poder pervertidas, sino en torno a una problemática insita en el corazón mismo de la Grecia clásica, especialmente en Platón» (R. RochliTz, «Esthétique de l'existence. Morale postconventionnelle et théorie du pouvoir chez Michel Foucault», en VARIOS, Michel Foucault philosophe. Rencontre internationale, Paris, 9, 10, 11 janvier 1988 [Paris 1989] 292). Con gran precisión y brillantez, a partir de la categoría de parresía (decir la verdad), aborda FouCAULT el problema de la verdad en Grecia, en su obra Discourse and Truth. The Problematization of Parrhesia, que recoge, compiladas por Joseph PEARson, las lecciones dictadas a finales de 1983 por el propio Foucault en el Departamento de francés de la Universidad de California, en Berkeley, bajo la coordinación del Prof. Paul RaBinow. Desde la centralidad que en su pensamiento supone buscar, encontrar y decir la verdad, FouCAULT polemiza con los reductores de su pensamiento, tanto contra el simplismo de quienes piensan que para él es imposible llegar a conocer plenamente la verdad, porque no existe; como contra quienes estiman que los denominados «juegos de verdades», es decir, el conjunto de reglas que la producen o descubren, no son en su pensamiento más que relaciones de poder, entendidas como «estados de dominación» o relaciones unilaterales y unidireccionales entre dominantes y dominados, basadas generalmente en la violencia que, en principio, excluyen cualquier intento de condicionamiento recíproco $\mathrm{y}$, por tanto, de búsqueda y encuentro con la verdad. 
más elemental hasta el hombre. El pluralismo, en esta perspectiva, no va más allá de ser la simple constatación, social y jurídicamente aséptica, de una realidad que, por su evidencia y simplicidad, no presenta ningún problema especial.

Los problemas comienzan cuando del mundo de las meras constataciones y de la simple observación, en su sentido más objetivo, material y concreto, se avanza al ámbito antropológico, social, jurídico o religioso, para preguntarse por el pluralismo como medio de integrar la unidad de lo que en una determinada sociedad se consideran valores humanos fundamentales en la diversidad o dispersión generadas por el ejercicio, ya individual o colectivo, de las libertades personales que, a su vez, son integrantes básicos y necesarios del patrimonio ético y jurídico constitutivo de su identidad personal y social.

\section{El pluralismo en su dimensión científica}

Los primeros filósofos griegos, los presocráticos, ya se plantearon el problema del pluralismo, no sólo desde su dimensión social, sino también desde la metodología o hermenéutica del progreso del conocimiento. Desde su teoría del conocimiento, explicaron la diversidad y multiplicidad de los fenómenos y realidades naturales por la existencia de un ser único y absoluto, auténtica fuente de la pluralidad cósmica; de este modo, describen, definen y justifican lo mudable (multiplicidad) por lo permanente (unidad). Socialmente, los griegos superaron la diversidad política, en la unidad de la ciudad (polis), a partir de una estructuración que integraba un conjunto de individuos procedentes de clases diferentes y orígenes dispares.

Sin embargo, ha de tenerse siempre muy presente que, para la concepción metodológico-científica de los griegos, la unidad era elemento determinante material y formal de todo su cosmos científico, dado que la unidad era, al mismo tiempo, razón/motivo de racionalidad y efecto principal y primario de la misma: no era posible ciencia sin razón y ésta opera reduciendo/sintetizando en unidad lo múltiple. Baste recordar la negativa rotunda de los pitagóricos a admitir ni siquiera la posibilidad de números irracionales, llegando incluso a condenar a muerte a quienes se mostraban partidarios de esta posibilidad.

También ha de tenerse en cuenta que el término pluralismo ni es unívoco en su significación, ni uniforme en su utilización. Las ciencias positivas, desde la química o la física hasta la astronomía, se enfrentan a la cuestión del pluralismo siempre que intentan clasificar fenómenos dispares en categorías homologables, observables y, en la medida de lo 
posible, generales o generalizables, en orden a interpretar racionalmente la diversidad en una visión unificadora.

\section{Perspectiva filosófica del pluralismo}

También la historia del pensamiento, sobre todo desde la metafísica, evoca nuevas dimensiones de esta categoría, sobre todo, desde que Plotino y los neoplatónicos dedican la mayor parte de su pensamiento al problema de la conciliación entre unidad y multiplicidad, a la relación entre lo UNO y lo MULTIPLE ${ }^{19}$.

En su significación sistemático-metafísica, pluralismo designa aquellas doctrinas filosóficas, o bien alguno de sus aspectos, en que se admiten como válidos principios diferentes, irreductibles, coexistentes y equivalentes entre ellos. Se opone contradictoriamente al monismo en cuanto doctrina o enseñanza que explica o reduce la realidad a un solo principio de comprensión. Bien entendido que, en la historia del pensamiento, más que de pluralismo, en sentido propio y estricto, se ha de hablar de dualismo que, además, casi siempre se ha planteado desde la perspectiva del monismo, considerándolo su contrario: tal es el caso, entre otros, del dualismo pitagórico, platónico, cartesiano o kantiano.

19 «Todos los seres tienen su existencia por el Uno, no sólo los seres así llamados en el primer sentido, sino los que se dicen atributos de esos seres. Porque ¿qué es lo que podría existir que no fuese uno? Si lo separamos de la unidad, deja inmediatamente de existir...

Siendo la naturaleza del Uno engendradora de todas las cosas, no es en modo alguno ninguna de las cosas que engendra. No es algo que pueda tener cualidad y cantidad; ni es por otra parte inteligencia o alma, ser en movimiento o en reposo, ser en el lugar o en el tiempo. Es simple por sí misma, y mejor aún, algo sin forma que está antes de toda forma, antes de todo movimiento y de todo reposo; estas cualidades son las que, precisamente, se encuentran en el ser y le hacen múltiple...

La mayor de las dificultades para el conocimiento del Uno estriba en que no llegamos a El ni por la ciencia ni por una intelección como las demás, sino por una presencia que es superior a la ciencia. El alma se aleja de la unidad y no es en absoluto una cuando aprehende algo de modo científico; porque la ciencia es un discurso y el discurso encierra multiplicidad. El alma entonces excede la unidad y cae en el número y en la multiplicidad. Convendrá, pues, remontar la ciencia y no abandonar nunca ese estado de unidad...

Nos encontramos de este modo con una multiplicidad en la que todo está reunido; esto es, el mundo inteligible... Ese mundo resulta superior al alma, pero no es, sin embargo, lo primero, por carecer de unidad y de simplicidad. El Uno es lo único que es simple y es también, por esa su simplicidad, el principio de todas las cosas... ese Uno, ciertamente, es algo más admirable que la Inteligencia y no cabe siquiera que le llamemos ser, para no considerar el Uno atributo de ninguna cosa» (Enéada sexta). 
El recurso al pluralismo, como tal, sólo se planteó de manera excepcional en algunos casos: Empédocles ${ }^{20}$, Anaxágoras ${ }^{21}$, gnósticos ${ }^{22}$ y maniqueos; o bien se utilizó como respuesta coyuntural a algún problema

${ }^{20}$ Para Empédocles, todo lo existente está radicalmente integrado/fundado en/por cuatro elementos primigenios absolutamente distintos entre sí, a causa de fuerzas distintas, tanto en los períodos cósmicos en que la philia produce su mezcla o unión como en los que la neikos los divide y opone (Cf. ARIstóteles, Metaphysica, I, 4, 8-9, 984.a). Elementos que son, además, raíz gnoseológica de todas las cosas, de la vida del cosmos (sol, tierra, cielo y mar) y de la propia idea y relación entre los dioses (Zeus, Hera, Aidoneo y Nestis). Al pluralismo de las sustancias elementales, se une el dualismo de las fuerzas naturales: una que tiende, por composición, a la unidad del mundo, según la mente divina; y otra que, por distensión, da origen a la diversidad de los seres. Desde la sistemática pluralista, y aunque pudiera parecer lo contrario, Empédocles va más allá que los atomistas, pues, para éstos, si bien la realidad es cuantitativamente múltiple o plural, sin embargo, el principio formal del que se valen para explicarla es uno, el átomo que gira en el vacío. El pluralismo, pues, según Empédocles, radicaría en la relación alterna establecida entre lo Uno y lo múltiple, generándose uno de otro alternativamente y produciendo, de este modo, la transitoriedad de las cosas en la permanencia de las sustancias:

«Es imposible que se llegue a ser a partir de lo que de ninguna manera es e imposible e increíble que el ser perezca, pues siempre habrá algo en lo que uno pueda apoyarse» (Frag. en PluTARCO, DK 31, B 12)

«Escucha primero las cuatro raíces de todas las cosas: Zeus resplandeciente; Hera, la que da vida, Edoneo y Nestis, que con sus lágrimas hacen fluir las fuentes de los mortales» (Frag. en AELIO, DK 31, B 6)

«Y este cambio continuo nunca cesa, congregándose todas las cosas, unas veces por acción del Amor, separándose otras veces entre sí por el rencor de la Discordia» (Frag. en Simplicio, DK 31, B 17)

«Con la tierra conocemos la tierra; con el agua, el agua; con el éter, el divino éter; $y$ con el fuego, el fuego destructor; con el Amor, el Amor, y la Discordia, con la luctuosa Discordia» (Frag. en ARISTóteles, B 4, 1000, b 6)

(Cf. J. Burnet, Early Greek Philosophy, Londres 1930, 197-250; N.-K. FreEMAn, The Presocratic Philosophers, Oxford 1946, 172-203; W.K.C. GuTHRIE, A History of Philosophy, vol. 2, Cambridge 1965, 122-265; G.S. KIRK y J.E. RAVEN, Los filósofos presocráticos, Madrid 1969, 447-503; H.S. Long, «The Unity of Empedocles Thougt», American Journal of Archaeology, 1949, 142-158).

21 Anaxágoras extiende su pluralismo diverso y multiforme a todas las cualidades y características de las cosas, tanto en su dimensión o aspectos orgánicos como inorgánicos, entendiendo la realidad como una infinidad de elementos heterogéneos y considerando homogéneas sólo las partículas de cada uno de ellos (omeomerías). Al conjunto de las omeomerías se opone el Nous, que ordena el mundo y determina su finalidad por medio de su naturaleza inteligente:

«Todas las cosas estaban juntas, infinitas en número y pequeñez: pues lo pequeño era también infinito. Y estando todas juntas, nada era visible, a causa de su pequeñez; pues el aire y el éter, ambos infinitos, las cubrían a todas, ya que éstos son la materia que más se contiene en todas las cosas, tanto en número como en magnitud» (Frag. en SiMPLICIO, DK 59, B 1) 
concreto, como fue, por ejemplo, la explicación de la multiplicidad de mundos. Sólo a partir de la filosofía de Leibniz comienza la articulación sistemática del pluralismo como medio o método de acercamiento a la realidad y de reflexión sobre la misma.

Cuestión que renace en una de las discusiones más aceradas y famosas del pensamiento medieval: el problema o querella de los universales $^{23}$. Y que, desde una problemática distinta, también se plantea en el averroísmo con su teoría de la generalización de la realidad universal del espíritu humano: para Averroes, así como existe una idea de hombre que se concreta y realiza en el alma humana, sólo existe un alma espiritual para toda la humanidad, tan distinta de la materia que no puede ser individualizada por el cuerpo.

«Los griegos no atinan al admitir el nacer y el perecer. Pues ninguna cosa nace ni perece, sino que resulta de la mezcla de seres ya existentes, y en ellos se disuelve; y así, mejor llamaríamos al nacer composición y al perecer disolución» (Frag. en SIMPLICIO, DK 59, B 17)

«Pero la Mente, que siempre es, está también con toda certeza donde están todas las cosas, en la pluralidad circundante y en las cosas que han sido unidas y en las separadas» (Frag. en SimPLICIO, DK 59, B 14)

(Cf. P. O. BRIEN, «The relation of Anaxagoras and Empedocles», The Journal of Hellenic Studies 88, 1968, 93-103; J.C. BuRnET, o.c., p. 251-275; N.K. FrEEMAN, o.c., p. 205-211; W.K.C. GUTHRIE, o.c., p. 266-338; G.S. KIRK y J.E. RAVEN, o.c., p. 504-548).

${ }^{22}$ La cuestión de la multiplicidad de los mundos, forma relevante en el planteamiento del pluralismo y uno de los casos sin resolver por Aristóteles que condenó todas las doctrinas que se decantaban por la multiplicidad de mundos coexistentes en el espacio o sucesivos en el tiempo, adquiere una gran importancia en el pensamiento gnóstico de mano de la doctrina de los eones, en cuanto épocas o períodos sucesivos de la emanación divina, dirigidos y determinados cada uno por un principio propio (Cf. A. ORBE, Antropología de San Ireneo, Madrid 1969; Idem, Cristología gnóstica. Introducción a la soteriología de los siglos II y III, 2 vols., Madrid 1976; Idem, Introducción a la teología de los siglos II y III, Roma-Salamanca 1988; G. RodríGUEZ DE YURRE, Historia de la filosofía griega, Vitoria 1954, 57-65, 78-102 y 301-313).

23 «Se entiende en filosofía por universales las también llamadas nociones genéricas, ideas y entidades abstractas... Los universales se contraponen, pues, a los particulares, o entidades concretas. El problema capital que presentan es el de su status ontológico... Aunque... se trata primordialmente de una cuestión ontológica, ha tenido importantes implicaciones y ramificaciones en otras disciplinas: la lógica, la teoría del conocimiento y hasta la teología. La cuestión ha sido planteada con frecuencia en la historia de la filosofía... pero como fue discutida muy intensamente durante la Edad Media suele colocarse en ella el origen explícito de la llamada cuestión de los universales... El interés mostrado en la actualidad por el problema de los universales no es simplemente el resultado de una curiosidad histórica, sino la consecuencia del hecho de que se trata de una cuestión capital filosófica, que afecta desde la índole de las entidades matemáticas hasta el status ontológico de los valores» (J. FERRATER Mora, Diccionario de Filosofía, Buenos Aires $^{4}$ 1958, 1363-1364). 
Nominalismo y averroísmo representan dos soluciones extremas a la cuestión de la unidad en la diversidad: mientras aquél diluye en la nada la virtualidad de los conceptos universales, reduciéndolos a meros flatus vocis ${ }^{24}$; el segundo, deshace la multiplicidad y diversidad de las personas, así como su singularidad, en la unidad universal de un alma

${ }^{24}$ En la referida disputa de los universales, sin entrar en este lugar en las apreciables diferencias entre el nominalismo de Guillermo de Ockam y el de Roscelino de Compiège, la posición de los medievales puede sintetizarse en los siguientes términos: para el nominalismo, especies y géneros no son realidades anteriores a los individuos, sino simples voces o nombres que designan conjuntos de cosas. Según éstos, lo real es únicamente el ser individual, el ente singular, la sustancia primera. Ahora bien, ha de tenerse presente que, aunque el nominalismo medieval consista primaria y principalmente en la negación de la prioridad real de especies y géneros, el contenido de su filosofía es mucho más complejo. Por ello, se ha de ser muy cuidadoso a la hora de no identificar y confundir todas las formas de nominalismo, incluso aquellas que aparecen, bien simultáneamente, bien en inmediata sucesión en la misma época (Cf. P. VignauX, «Nominalisme», en A. Vacant, E. Mangenot y E. Amann (dir.), Dictionnaire de Théologie Catholique, t. 11, Paris 1931, col. 717-784; por lo que se refiere más directamente a los universales, col. 717-741). Algunos autores contemporáneos han recuperado o resaltado, bien es cierto que no sin polémica, la aportación a la moderna teoría de los derechos individuales o subjetivos realizada a partir de la aplicación directa e inmediata de la hermenéutica nominalista al mundo del derecho, dentro del contexto histórico-eclesiológico de la conocida como disputa franciscana en torno a la pobreza de Cristo y de sus discípulos, así como de la Iglesia y de las propias comunidades o fraternidades franciscanas. Así como carecería de sentido hablar del contrato, o del testamento o de la paternidad, sino que habría que referirse a tal o cual contrato, a los diferentes y posibles testamentos y a cada uno de los individuos que son padres; otro tanto ocurriría con el derecho, que no tendría razón de ser en cuanto objetivación genérica y universal, sino que adquiere verdaderamente realidad, interés y efectividad cuando se realiza y sustantiva en un sujeto concreto; es decir, en un individuo (Cf. P. Grossi, L'ordine giuridico medievale, Roma-Bari 1999, 72-78 y 80-84; A. JA. GUREVIC, La nascita dell'individuo nell'Europa medievale, Roma-Bari 1996, 6-30 y 105-147; L. PARISOLI, "Guglielmo di Ockam e la fonte dei diritti naturali: una teoria política tra libertà evangelica e diritti fondamentali ed universali», Colectanea Franciscana 68, 1998, 5-61; Idem, Volontarismo e diritto soggettivo. La nasita medievale di una teoria dei diritti nella scolastica francescana, Roma 1999; Idem, La philosophie normative de Jean Duns Scoto. Droit et politique du droit, Roma 2001). M. VILley ha tratado con gran detenimiento esta cuestión en parte de sus publicaciones, advirtiendo que sus resultados no se han recibido exentos de polémica todavía viva. Entre éstas, cabe señalar: «L'idée du droit subjectif et les systèmes juridiques romaines», Revue historique de droit 24, 1946, 201-228; «Du sens de l'expression ius in re en droit romain classique», Revue internationale des droits de l'antiquité, 1949, 417-436; «Le ius in re du droit romain classique au droit moderne», Publications de l'Institut de droit romain de l'Université de Paris 6, 1950, 187-225; La formation de la pensée juridique moderne (Paris 1975) 157-224. Sobre algunos aspectos y momentos de la polémica señalada, aunque el autor que citamos sigue el pensamiento de Villey en esta cuestión, puede verse S. FerLITO, Diritto soggettivo e libertà religiosa. Riflessioni per uno studio storico e concettuale (Nápoles 2003) 31-32, nt. 34 y pp. 32-44. 
común a todos los humanos, en clara contradicción con la personal experiencia de la autopercepción de la propia individualidad ${ }^{25}$.

De vía intermedia podría calificarse la solución de SANTO TOMÁs, para quien el universal, en cuanto tal, sólo existe en el pensamiento humano y únicamente se da particularizado en la realidad múltiple y plural del universal concreto. Esta individuación o individualidad del universal se nos presenta, en la realidad, como portador de una esencia o naturaleza que, en cuanto realidad permanente de su existencia, la religa y relaciona con el resto de individuos de su propia especie, posibilitando su clasificación e identificación científicas.

La evolución experimentada por la metafísica en época moderna posibilitó y facilitó no sólo la delimitación teórica de las coordenadas del pluralismo en cuanto idea filosófica, sino su aplicación en cuanto fenómeno o contraste social y político, sin excluir, como es lógico, las consecuencias e incidencias jurídicas implicadas en una y en otros. En concreto, difícilmente se podría hoy reflexionar sobre el pluralismo, si no nos hubieran precedido:

a) la teoría de SpInOza cuando afirma que los atributos de la sustancia son infinitos y que sólo podemos conocer dos de ellos, el pensamiento y la extensión;

b) la monadología de LEIBNIZ, que describe la realidad como un conjunto infinito de mónadas o unidades de energía en desarrollo, cada una de las cuales es totalmente independiente de las otras y difiere de todas las demás por su representación, consciente o inconsciente, de todas las otras: Dios es la Mónada absoluta, energía perfecta en acto puro, que crea todas las mónadas en armonía, preestablecida y elegida por El entre infinitos mundos posibles;

c) la concepción kantiana del mundo moral como una «república de los espíritus» ${ }^{26}$, sujetos únicamente a la justicia divina, pero libre cada uno en la aceptación del deber;

25 Sostiene Averroes que la contradicción que implica la identificación de la inteligencia actuante (pensante) con lo inteligible pensado por ella debe solucionarse mediante la suposición de que toda acción intelectual humana es simple participación en un solo y único entendimiento agente. Sólo este entendimiento y su radical unidad y exclusividad, en cuanto uno, posibilita que el entendimiento pasivo (múltiple en su concreción histórica) pueda desprenderse de su condición temporal y limitada, elevándose hasta aquel. En consecuencia, no puede hablarse de supervivencia o inmortalidad personal, en el sentido de que cada entendimiento llegue individualmente a la contemplación del agente supremo, sino que llega a él no por la contemplación, sino en la fusión con él (Cf. R. DE VAUX, «La première entrée d'Averroès chez les Latins», Revue des Sciences philosophiques et théologiques 22, 1933, 193-242).

26 I. KANT, Anthropologie, I, 2. 
d) las opciones del espiritualismo crítico y romántico que asumieron como idea matriz la pluralidad de las ciencias, en oposición a su unificación dialéctica desarrollada, sobre todo, por el idealismo trascendente y absoluto.

Del mismo modo que se ha de tener muy claro que, incluso en el ámbito del pensamiento filosófico, el pluralismo no ha conseguido todavía articular las garantías que posibiliten el desarrollo de la multiplicidad de perspectivas y prospectivas por él mismo postuladas; se ha de considerar adquisición irrenunciable del pluralismo y continua referencia crítica de la sociedad el principio de que la unidad del mundo no excluye la multiplicidad de las perspectivas ontológicas y lógicas desde la que se intenta comprenderlo; antes al contrario, las genera analíticamente.

\section{Pluralismo, persona y sociedad}

En la persona humana se verifica, quizás como en ningún otro ser, la dialéctica entre el uno-universal-único y el particular-plural-múltiple, dado que concreta, en grado máximo, a causa de su dualidad constitutiva, la singularidad y el particularismo, al tiempo que necesariamente ha de realizarlo y realizar-se comunitaria o socialmente.

Cada persona es un todo único y singular. Unidad y unicidad que, hemos de reconocer, es la fuente y origen del profundo deseo que cada ser humano tiene de ser y verse reconocido en su dignidad y singularidad. Es una constante en la experiencia personal que, precisamente, el reconocimiento social es la mejor garantía de estima personal. Sin embargo, no puede olvidarse la paradoja en que se desenvuelve la naturaleza humana al necesitar perentoriamente de otras realidades y de otras personas, es decir de la sociedad, para alcanzar y satisfacer sus fines personales. Esta dimensión social de la naturaleza humana se traduce y concreta en la existencia de una verdadera y auténtica comunidad humana; y si se puede hablar de comunidad es porque en cada uno de sus miembros existe, más allá o además de sus exclusivas características o propiedades personales, un constitutivo común con los demás.

La progresiva importancia que en el mundo actual se atribuye a los derechos del hombre es muestra incontestable de cómo lo que existe de común en las personas prevalece sobre lo singular y particular, dado que la alteridad no es sólo ni principalmente característica o propiedad de la naturaleza humana, sino constitutivo esencial de su ser-persona: miembros de una misma comunidad, los aspectos particulares y plurales o disgregadores (raza, cultura, ideología, religión, etc.) no pueden 
eclipsar el fundamento común que nos relaciona esencial y radicalmente a unos con otros.

En profunda relación con esta dimensión personalista, cabe hablar de un pluralismo social, no en el sentido de que la simple constatación de cualquier diferencia social pueda considerarse equivalente o sinónimo de pluralismo social, sino en cuanto que la sociedad, por su supeditación al servicio de la persona, ha de manifestar y responder a la compleja pluralidad constitutiva del ser-personal. Pensar que pluralismo social se encuentra en relación con diversificación social o con la variedad de sociedades existente y constatable en nuestro entorno es asumir una concepción superficial, externa, reduccionista del pluralismo; pues cabe perfectamente la ausencia de pluralismo en el entorno de una pluralidad de sociedades, ya que no por estar fragmentada es pluralista ninguna sociedad.

Para que una sociedad pueda considerarse pluralista ha de estar integrada en sus miembros por personas que hayan accedido a la misma libre y voluntariamente, sin que el ingreso en o la salida de la misma se impida por ningún motivo de exclusividad: apertura y libertad son las dos condiciones que caracterizan a una sociedad como pluralista, que no significa mera equivalencia o equipolencia con la variedad o pluralidad de sociedades. El pluralismo social, pues, no es cuestión numérica, cuantitativa o de simple variedad, sino de carácter cualitativo, interno, de estructura, constitución y funcionamiento de cada sociedad concreta.

\section{Pluralismo y política}

En la ciencia política y en la sociología, se ha entendido por pluralismo bien la doctrina política opuesta a la teoría monista del Estado, o bien una hermenéutica de análisis y comprensión de las sociedades e instituciones humanas distintas del Estado. El pluralismo moderno, sobre todo tal y como se ha desarrollado en Inglaterra y América entre los años 1900 y 1930, surgió como consecuencia de la imposibilidad estructural que atenazó al Estado moderno a la hora de dar respuesta a importantes problemas surgidos de modos de organización social, hasta entonces, desconocidos, así como de las nuevas formas de articulación de los Estados ${ }^{27}$.

27 Para una visión comprensiva del fenómeno y del problema del pluralismo político tal como se ha venido manifestando a lo largo de la historia, así como su asunción e influencia en los ordenamientos constitucionales contemporáneos, puede verse D. LLAMAZARES FERNÁNDEZ, Derecho de la libertad de conciencia, vol. I. Libertad de conciencia y laicidad (Madrid 2002) 46, 110-180, 204-250 y 310-314. 
La teoría del Estado soberano, elaborada principalmente por juristas, provocaba graves dificultades desde el punto de vista político, sobre todo, en la medida en que soberanía se confundía con omnipotencia del Estado. El desacreditado Estado soberano fue el principal objetivo crítico de las teorías y doctrinas pluralistas que, desplazando su interés y punto de mira del Estado a la sociedad y grupos sociales, reivindicaron derechos y protagonismo social para grupos profesionales y asociaciones, en oposición al Estado ${ }^{28}$.

Desde la experiencia que aportan tanto la evolución de las ideas políticas como su concreción a lo largo de la historia, cabe afirmar, siempre desde las cautelas exigidas por las ciencias que versan sobre el hombre y su actividad, que la democracia contemporánea es esencialmente el triunfo del pluralismo no sólo en el ámbito de las ideas, sino también en el de los programas de acción política.

Tampoco ha sido ajeno a esta consolidación de la práctica democrática el progresivo reconocimiento de los derechos del hombre que, en cierto modo, ha despolitizado, en su sentido más estricto, el concepto de democracia para convertirlo en modo o marco en que delinear o tipificar las relaciones humanas, asumiendo como fundamento basilar de las mismas el respeto a la igual dignidad de todos los hombres y a sus ideas, aun cuando no se compartan: éste precisamente sería el punto de inflexión en que se entrecruzan tolerancia y pluralismo.

El ideal democrático, que en un primer momento aparece como conquista de la libertad política, evoluciona, como consecuencia de una necesaria dinámica interna, hacia la defensa y promoción de cualquier libertad, sobre todo de la de pensamiento: con el ideal democrático, necesariamente debía afirmarse la legitimidad, incluso la necesidad, del pluralismo. Precisamente de esa dimensión pluralista extrae su razón de ser el ideal democrático en cuanto proceso concurrencial y competitivo para hacer llegar al poder una verdad o una ideología: la misma fuerza que legitima y garantiza la lucha entre las ideas ha de impedir cualquier ataque contra las personas.

La propia imbricación estructural de ideas, libertad y persona que constituyen los elementos matrices del pluralismo implica y exige el establecimiento de ciertos límites autoprotectores del mismo pluralismo. En nombre del pluralismo, pues, no podrá destruirse lo que es

28 Cf. L. Duguit, Il diritto sociale, il diritto individuale e le trasformazioni dello Stato (Florencia 1950), que en la obra citada rechaza la concepción y teoría del Estado soberano, junto con las concepciones metafísicas del derecho, cuya finalidad ha de ser, según este autor, promover la solidaridad social. 
mínimamente común a todos los hombres como, por ejemplo, los derechos humanos; ni desembocar en un relativismo desmotivador y desmovilizador del compromiso y del esfuerzo por la mejora de la condición humana y del compromiso por la profundización, ampliación y extensión de los derechos fundamentales y básicos de todo ser humano.

También es importante, desde esta perspectiva política, acercarse al contenido y función del pluralismo como ambiente o caldo de cultivo que posibilite o facilite el ejercicio de la libertad, tanto en las relaciones interpersonales como desde las diversas concreciones de sus manifestaciones sociales. Relacionada con esta dimensión esencial del pluralismo, se plantea la cuestión de la tolerancia respecto al intolerante, en razón de que, en estos supuestos, el ambiente de libertad necesariamente implicado en y derivado del pluralismo actuaría de medio incubador del posible fin de la libertad que le da su fundamental razón de ser. Como hace algunos años se puso de relieve, quizás el problema de «la tolerancia del intolerante» sea, curiosa o trágicamente, más teórico que real, pues únicamente se plantea en aquellas sociedades donde, por los medios democráticos comunes, no es probable que el intolerante llegue a influir en la sociedad hasta tal extremo que acabe con la libertad, aunque así lo hayan hecho sus connacionales o correligionarios en los pueblos donde gobiernan; por otra parte, donde los regímenes políticos y sociales son radicalmente intolerantes no tiene sentido plantear la cuestión ${ }^{29}$.

\section{Futuro y perplejidad}

Sin embargo, a pesar de la claridad y contundencia con que autores como WALZER plantean y «solucionan» este problema, cabe preguntarse si hoy, después de experimentar la fuerza y alcance del terrorismo internacional y de sus distintas y variadas concreciones y manifestaciones, no habría que cambiar sustancialmente los parámetros en que se había movido con anterioridad el planteamiento de estas cuestiones. Ahora bien,

- ¿Sigue siendo válida esta postura cuando, a través de variadísimas formas de presión, desde la coyuntural «invasión» de ciertos

29 Cf. M. WALzer, On Toleration, New Haven-Londres 1997: la referencia realizada corresponde a las páginas 111-114 de la edición italiana publicada por Editorial Laterza el año 2000. Para una visión de estas cuestiones desde una perspectiva en que se intenta abarcar su dimensión política y cultural, puede verse A. CALvo EsPIGA, «Tolerancia, multiculturalismo y democracia: límites de un problema», Laicidad y libertades. Escritos jurídicos 3, 2002, 73-106. 
lugares o ámbitos sociales especialmente representativos hasta la actividad terrorista, las sociedades intolerantes exportan intolerancia mucho más allá de los límites geográficos de sus fronteras? - ¿Se puede utilizar esta solución cuando grupos significativos de una determinada cultura o ideología intolerantes invaden o copan espacios ciudadanos en que llega a hacerse muy molesta, e incluso imposible, la vida para el tolerante nativo que respeta, pero no acepta, vivir según los modos y planteamientos de aquellos?

— ¿Cómo responder, por ejemplo, al hecho de que las mujeres, incluso las ya ancianas, de una pequeña ciudad, de unos doce mil habitantes, no se atrevan ni siquiera a transitar por determinadas calles y lugares de $s u$ ciudad, en la que nacieron y han vivido siempre, habitados en este momento mayoritariamente por personas que de forma habitual las insultan y agreden verbalmente por su forma de vestir, de comportarse o de relacionarse con los varones?

- ¿Puede, en consecuencia, seguir afirmándose que un grupo intolerante es inocuo en un ambiente de tolerancia?

En definitiva, si como ha sido puesto de relieve, es cierto que en los últimos años se asiste, al menos en ciertos ambientes sociales y políticos, a un, siquiera tímido, proceso de desprivatización de lo religioso, correspondido con una progresiva presencia de lo religioso en lo público, no lo es menos que ello implica, para Occidente, un importante problema por cuanto respecta a determinados planteamientos de ciertas culturas religiosas que, como acontece, por ejemplo, en el caso del Islam, desafían tanto la propia formulación como la práctica de los derechos humanos, sobre todo en lo que atañe a su universalidad, como paradójicamente ya está aconteciendo en Francia, patria de la moderna concepción de los derechos del hombre ${ }^{30}$.

El progreso y desarrollo de la libertad no es una cuestión meramente jurídico-legal, aun cuando esta dimensión sea importante y necesaria,

30 Cf. S. Ferrari, «È cambiato il vento?», Quaderni di Diritto e Política Eclesiástica, 1995, 3-10; sobre todo, p. 4-5). En este sentido, cabe señalar que, por ejemplo, entre el 10 de mayo y el 5 de junio de 2003 se han publicado en el periódico Le Monde más de treinta colaboraciones relacionadas con la repercusión que la presencia masiva, en algunos lugares, de fieles islámicos está teniendo sobre la laicidad del Estado francés que, a un siglo de su consagración en la Ley de separación de 1905, ve tambalearse algunos de sus fundamentos histórica y aparentemente más seguros, consolidados y estables.

Redactados nota y texto antes de la elaboración y promulgación de la ley que prohíbe cualquier manifestación pública de simbología religiosa en la Escuela estatal francesa, no nos resistimos a señalar cómo acontecimientos posteriores han venido a confirmar lo acertado del diagnóstico. 
sino que en ellos han de ser asumidos las conquistas y avances realizados por las ciencias humanas, puesto que la libertad ha de realizarse fundamentalmente en el ámbito de las relaciones intersubjetivas y en el respeto e integración de la diversidad de los distintos grupos sociales: la auténtica y verdadera libertad, como se ha puesto de relieve por la sociología contemporánea, es la libertad en relación, una libertad que se active y actúe en la acción.

Precisamente la voluntariedad en la pertenencia o adscripción a un concreto grupo social garantiza la libertad frente al totalitarismo de integración necesaria en un clan. Ello, además, implica que sólo se posibilitará adecuadamente el ejercicio de la libertad en aquellas situaciones en que exista una auténtica diversidad de grupos que, a través de propiciar la variedad de opciones, posibiliten y promocionen la libertad ${ }^{31}$.

${ }^{31}$ Cf., para un planteamiento distinto y complementario de este concepto de pluralismo político, G. SARTORI, Pluralismo, Multiculturalismo e Estranei (Milán 2001) 22-24 y 31-36, junto con la bibliografía aportada en las páginas mencionadas. 